\title{
Bargaining with Incomplete Information: An Infinite-Horizon Model with Two-Sided Uncertainty
}

\author{
PETER C. CRAMTON \\ Stanford University
}

\begin{abstract}
The resolution of any bargaining conflict depends crucially on the relative urgency of the agents to reach agreement and the information each agent has about the others' preferences. This paper explores, within the context of an infinite-horizon bargaining model with two-sided uncertainty, how timing and information affect the rational behaviour of agents when commitment is not possible. Since the bargainers are uncertain about whether trade is desirable, they must communicate some of their private information before an agreement can be reached. This need for learning, due to incomplete information about preferences, results in bargaining inefficiencies: trade often occurs after costly delay. Thus, the model provides an explanation for the inefficient bargaining behaviour that appears to occur often in practice.
\end{abstract}

\section{INTRODUCTION}

This paper develops a model of the bargaining process in the spirit of Fudenberg and Tirole (1983) and Sobel and Takahashi (1983). In the basic model, a buyer and a seller are bargaining over the price of an object. As they bargain, their payoffs are discounted over time, so that both the buyer and the seller have an incentive to come to an early agreement. The process is complicated by the fact that each bargainer has incomplete information about the preferences of the other agent; thus, communication between the traders is an important aspect of their behaviour. The seller, when making an offer, must evaluate how the offer will reveal information to the buyer. Likewise, the buyer must interpret an offer as a signal of the seller's preferences and hence an indication of what to expect in subsequent rounds of negotiation.

Fudenberg and Tirole (1983) studied a two-period bargaining model with the traders private information described by a two-point distribution. The simple information structure and limited horizon enabled them to characterize the set of all sequential equilibria, and conclude that few (if any) comparative static results are true in all bargaining situations. Sobel and Takahashi (1983) analysed an infinite-horizon model with one-sided uncertainty in which the uninformed bargainer makes all the offers. By having the uninformed trader make all the offers, Sobel and Takahashi are able to avoid the complications of strategic communication that arise when a player with private information makes offers. This paper extends the analysis of Fudenberg and Tirole and Sobel and Takahashi by considering an infinite-horizon model, with one party making all the offers, in which both bargainers have private information.

The advantage of analysing an infinite-horizon model is that the bargaining is able to continue so long as each bargainer expects gains from continuing. Thus, negotiations need not end in a situation of ex post regret, in which the negotiators walk away from positive potential gains. Even when the players are better off (ex ante) restricting negotiations to a finite number of periods, if they are unable to commit to walking away from the bargaining table, they must adopt strategies that allow the possibility of negotiations continuing indefinitely.

When the bargainers' valuations are uniformly distributed, I construct a sequential equilibrium such that bargainers expecting larger gains from trade (who therefore are more impatient) reach agreement before those expecting smaller gains. The fundamental results are that:

Incomplete information leads to bargaining inefficiency.

Inefficiencies increase as preferences become more uncertain.

Bargainers with high delay costs are at a disadvantage.

Information is revealed more quickly, the higher the delay costs.

Although these intuitive results are all derived for the special case in which the potential gains from trade are uniformly distributed, many of the results are true in more general settings as well. For example, the conclusion that incomplete information leads to bargaining inefficiency has been observed in numerous economic models with incomplete information. On the other hand, the result that bargainers with high delay costs are at a disadvantage is not true for all distributions of the gains from trade. Fudenberg and Tirole (1983) have shown that at least in a two-period model it is possible for a player to benefit from a higher delay cost. Perhaps the most novel result is the form of the equilibrium I derive: information is revealed gradually over time and the rate of revelation depends on the players' costs of delay. In previous bargaining models with incomplete information, the 
communication process was either not modeled (as in static models and models with one-sided uncertainty) or the learning was cut short due to a restricted bargaining horizon (as in two-period models).

\section{THE MODEL}

A buyer and a seller are bargaining over the price of an object which is worth $s$ to the seller and $b$ to the buyer. At every stage of the game, the seller makes an offer $p$, which the buyer may accept or reject. Should the buyer accept the offer, the object is exchanged at the price $p$; whereas, a rejection by the buyer prompts the seller to make another offer in the next stage of the game. Both the buyer and the seller have costs of delaying the bargaining process. Specifically, their payoffs in the subsequent rounds are discounted according to the discount factors $\delta_{b}$ for the buyer and $\delta_{s}$ for the seller, with $0<\delta_{b}, \delta_{s}<1$. Thus the payoffs, if the buyer accepts the $t$ th offer $p$, are $\delta_{b}{ }^{t-1}(b-p)$ for the buyer and $\delta_{s}^{t-1}(p-s)$ for the seller. Should they fail to reach agreement, both players receive zero.

The buyer, though aware of his own valuation $b$, does not know the seller's valuation $s$, but assesses it to be given by the distribution $F(s)$, with a positive density $f(s)$ on $[\underline{s}, \bar{s}]$. Similarly, the seller knows her valuation $s$, but can only assess the buyer's valuation to be given by the distribution $G(b)$, with a positive density $g(b)$ on $[\underline{b}, \bar{b}]$. The discount factors, the distributions of the traders' valuations, and the structure of the game are common knowledge. In addition, it is assumed that both the buyer and the seller are solely interested in maximizing their expected monetary gain.

Rationality is assumed by requiring that the bargaining strategies of the agents form a Bayesian Nash equilibrium (Harsanyi (1967)): each player's strategy must be a best response to the other's strategy, given their probabilistic beliefs of the state of the world. I further require that their behaviour be sequentially rational (Kreps and Wilson (1982)): at every stage of the game, the players must play optimally, given their beliefs, for the remainder of the game. Thus, players are unable to commit to strategies they would not wish to carry out.

I derive an equilibrium in which the bargainers reveal gradually their private information over time. At each stage $t$ of the game, the buyer accepts the seller's offer $p_{t}$ if his valuation is greater than some cutoff valuation $\hat{b}_{t}\left(p_{t}\right)$ (if the buyer's valuation is less than $\hat{b}_{t}\left(p_{t}\right)$, he is better off holding out for lower offers in the future).

Thus, a rejection by the buyer indicates to the seller that the buyer's valuation is less than $\hat{b}_{t}\left(p_{t}\right)$. The equilibrium form of the seller's strategy is to make an offer $p_{t}(s)$ that is strictly increasing in $s$ (and hence completely revealing) if her valuation is less than some cutoff level $\hat{s}_{t}$, and otherwise (if her valuation is greater than $\hat{s}_{t}$ ) to simply delay negotiations by making an offer that no potential buyer will accept.

In sequential games with incomplete information, players typically have an incentive to hide their private information. Thus, the seller would like to tell the buyer, "My valuation is high, so you better expect to pay a high price", regardless of whether or not the seller's valuation is in fact high. The buyer, of course, is aware of the seller's incentive to deceive and hence will not believe statements that are not backed up by actions. The seller, in order to convince the buyer that she has a high valuation, must take actions that a low-valuation seller would be unwilling to imitate (as in a signalling problem such as Spence (1974)). Intuitively, this is why the seller reveals her private information in the way she does. Since a low-valuation seller is expecting large gains from trade, she is more impatient than if her valuation was higher, so she is unwilling to delay agreement. If the seller has a high valuation, she is able to convince the buyer of this fact by making high offers that delay agreement.

As the seller's valuation increases, she will make higher and higher offers, which are accepted by fewer and fewer buyers. At some point $\left(s=\hat{s}_{t}\right)$, the seller makes an offer that no buyer will accept, since every buyer is better off waiting for lower prices in the future. All sellers with valuations $s>\hat{s}_{t}$ are then unable to reveal their private information in the current round: a seller with valuation $s^{\prime}>\hat{s}_{t}$, cannot convince the buyer that she has a valuation $s^{\prime}$, since she has no way to back up her statement with actions that a seller with a different valuation $s>\hat{s}_{t}$ would be unwilling to take (no matter what offer $p>p_{t}\left(\hat{s}_{t}\right)$ is made, the buyer's response is the same).

Exactly how much information is revealed in each round of negotiations will depend on the bargainers' costs of delay. If delay costs are high, more information will be revealed because the punishment to a low-valuation seller of pretending to have a higher valuation is greater; whereas, if the seller's delay cost is low $\left(\delta_{s}\right.$ close to one), then less information will be revealed by the seller, since she is more willing to delay agreement by offering higher prices. 


\section{GENERAL CHARACTERIZATION OF EQUILIBRIA}

A sequential equilibrium consists of functions that determine the players' optimal strategies given their information about how the game has evolved for each information set, including information sets off the equilibrium path. At each stage $t$, the seller chooses an optimal price schedule $p_{t}(s)$ given her valuation $s<\hat{s}_{t}$ and her belief that the buyer's valuation is distributed on $\left[\underline{b}, \hat{b}_{t-1}\right]$ with density $g$. When $s \geq \hat{s}_{t}$, she simply delays by making a nonserious offer $p>p_{t}\left(\hat{s}_{t}\right)$. [For notational simplicity, I omit the functional dependence of the players' strategies on parameters of the model that are known and constant throughout the game, such as $\delta_{s}, \delta_{b}, \underline{b}, \bar{b}, \underline{s}$ and $\bar{s}$ ]. The buyer then decides to accept or reject the offer $p_{t}$ given his own valuation $b$; i.e. the buyer chooses a binary function $a_{t}\left(p_{t}, b\right) \in\{$ accept, reject $\}$. This strategy can be simplified to an indifference valuation $\hat{b}_{t}\left(p_{t}\right)$, since a cutoff strategy in which a buyer accepts the offer if and only if $b \geq \hat{b}_{t}\left(p_{t}\right)$ is optimal for the buyer, as derived in Lemma 1.

Lemma 1. At every stage $t$, the buyer employs a cutoff strategy in which he accepts an offer $p_{t}$ if and only if his valuation $b$ is less than some cutoff valuation $\hat{b}_{t}\left(p_{t}\right)$. Thus, the seller's posterior belief of the buyer's valuation is $G(b) / G\left(\hat{b}_{t}\right)$ at time $t$.

Proof. Define $V\left(b, H_{t}\right)$ to be the equilibrium expected payoff at time $t+1$ of a buyer with valuation $b$ after a history $H_{t}$, and let $Q\left(b, H_{t}\right)$ be the discounted probability of trade for the buyer $b$ after a history $H_{t}$. Suppose a buyer with valuation $b$ chooses to accept the offer $p_{t}$. Then $b-p_{t} \geq \delta_{b} V\left(b, H_{t}\right)$. Now consider a buyer with valuation $b^{\prime}>b$. We wish to show that the buyer $b^{\prime}$ will prefer to accept $p_{t}$; that is, $b^{\prime}-p_{t} \geq \delta_{b} V\left(b^{\prime}, H_{t}\right)$. Buyer $b$ can follow the equilibrium strategy of buyer $b^{\prime}$, but it must be the case that buyer $b$ does at least as well by following his own equilibrium strategy than that of buyer $b^{\prime}$. Thus,

$$
V\left(b, H_{t}\right) \geq V\left(b^{\prime}, H_{t}\right)-\left(b^{\prime}-b\right) Q\left(b^{\prime}, H_{t}\right) \geq V\left(b^{\prime}, H_{t}\right)+b-b^{\prime},
$$

and so

$$
b-p_{t} \geq \delta_{b}\left[V\left(b^{\prime}, H_{t}\right)+b-b^{\prime}\right],
$$

or

$$
\delta_{b} b^{\prime}+\left(1-\delta_{b}\right) b-p_{t} \geq \delta_{b} V\left(b^{\prime}, H_{t}\right)
$$

Since $b^{\prime}>\delta_{b} b^{\prime}+\left(1-\delta_{b}\right) b$, this yields

$$
b^{\prime}-p_{t} \geq \delta_{b} V\left(b^{\prime}, H_{t}\right)
$$

which implies that any buyer with valuation greater than $b$ strictly prefers to accept $\mathrm{p}_{\mathrm{t}}$ now, rather than wait for future offers. ||

When determining whether or not to accept or reject the offer $p$, the buyer must make an inference about the seller's valuation: What information does the offer $p$ reveal about the seller's valuation? This inference then determines what prices the buyer expects in the future, which enables him to calculate whether he should accept the price $p$ now or wait for lower prices in the future. Should the buyer observe a price $p$ in the range of the equilibrium price schedule $p_{t}(s)$, then the buyer will update his prior belief of the seller's valuation using Bayes' rule. If, however, the buyer observes a price $p$ not in the range of $p_{t}(s)$, then he cannot use Bayes' rule to update his prior. Rather he must update his prior based on conjectures he has about the seller's valuation when he is surprised by nonequilibrium behaviour. These conjectures are needed to determine the buyer's best response to behaviour off the equilibrium path, which in turn is used to evaluate the seller's benefits from deviating from the equilibrium. Of course in equilibrium, the seller is better off offering $p_{t}(s)$ than deviating, since the seller's price schedule is a best response to the buyer's strategy.

At every stage of the game, the strategies are similar: the seller chooses an optimal price schedule $p_{t}$ and cutoff level $\hat{s}_{t}$ given the history of events, the buyer chooses an indifference valuation $\hat{b}_{t}$, given the history of events, and the buyer maintains a set of conjectures $\mu_{t}$ that determine his beliefs about the seller's valuation should he observe nonequilibrium behaviour. No such conjectures are necessary for the seller since in 
equilibrium the buyer always rejects with positive probability and an acceptance ends the game. A sequential equilibrium, then, in the infinite-horizon bargaining game with two-sided uncertainty is the collection

$$
\left\{p_{t}(\cdot), \hat{s}_{t}(\cdot), \hat{b}_{t}(\cdot), \mu_{t}(\cdot)\right\}_{t=\infty}^{\infty}
$$

where $\mu_{t}\left[s \mid p \notin p_{t}\left(\left[\underline{s}, \hat{s}_{t}\right]\right)\right]$ is a probability distribution representing the buyer's conjectures about the seller's valuation, conditioned on the event that the seller offered a price $p$ that is not in the range of the equilibrium price schedule $p_{t}(\cdot)$. The equilibrium strategies $p_{t}, \hat{s}_{t}$, and $\hat{b}_{t}$, and the conjectures $\mu_{t}$ must be such that at time $t$ : (1) the buyer $\hat{b}_{t}(p)$ is indifferent between accepting or rejecting the price $p$ given his expectations of future prices based on his inference of the seller's valuation, (2) the offer $p_{t}(s)$ of seller $s$ is optimal for the seller given that the buyer's valuation is distributed according to the distribution $G(b) / G\left(\hat{b}_{t-1}\right)$ with support $\left[\underline{b}, \hat{b}_{t-1}\right]$, and (3) the conjectures $\mu_{t}$ imply that the seller $s$ is better off offering the equilibrium price $p_{t}(s)$ than deviating by offering a price not in the range of the equilibrium price schedule $p_{t}$.

A property that is very reasonable, but which cannot be proven in general, is that a seller with higher valuations offers higher prices. This is certainly true in the one-shot game, but in the multi-period game the buyer might have strange beliefs that could sustain an equilibrium in which price does strictly decrease with $\mathrm{s}$ in some period. However, I do not allow the buyer to maintain such beliefs, and so restrict attention to monotonic equilibria.

\section{EQUILIBRIUM BEHAVIOUR WITH THE SELLER'S VALUATION KNOWN}

In periods following the seller's revelation of her private information, the players' behaviour will be the same as in the game in which the buyer knows the seller's valuation s, and the seller knows only that the buyer's valuation is uniformly distributed on $[\underline{b}, \hat{b}(p)]$. Thus, to determine a separating equilibrium for the game with two-sided uncertainty, it is necessary to first determine an equilibrium in the game with one-sided uncertainty.

Assume that the seller's valuation s is known to the buyer, but the seller only knows that the buyer's valuation is uniformly distributed on $[\underline{b}, \bar{b}]$ (without loss of generality, we can assume that $s \leq \underline{b}$, for any buyers with $b<s$ would not enter negotiations). I begin by determining the equilibrium for the $n$-stage game, and then establish an equilibrium in the infinite-horizon game by letting $n$ go to infinity. It will turn out that the form of the infinitehorizon bargaining equilibrium will depend on whether $s=\underline{b}$ or $s<\underline{b}$. With $\mathrm{s}=\underline{b}$, prices strictly decrease over time and eventually converge to (but never reach) $\underline{b}$. With $s<\underline{b}$, after some finite number of periods, the seller offers the price $p=\underline{b}$, which is accepted by the buyer with probability one, thus concluding the bargaining. For the sake of brevity, I will only present the case where $s=\underline{b}$.

The players' equilibrium behaviour (a sequence of prices for the seller and a sequence of indifference valuations for the buyer) is determined by solving a dynamic programming problem in which the seller chooses the offer that maximizes her present value of current and future gains, given her knowledge of the buyer's valuation, and subject to the constraint that the buyer will accept the offer only if his valuation is sufficiently high that he is better off accepting now than waiting for lower prices in the future. Namely, with $i$ periods remaining in the $n$-stage bargaining game, define $j$ to be $n+1-i$, so the seller chooses $p_{j}$ to maximize her expected gain $u_{\mathrm{j}}(s$, $b_{j-1}$ ) given that the buyer's valuation is uniformly distributed on $\left[\underline{b}, b_{j-1}\right]$ :

$$
u_{j}\left(s, b_{j-1}\right)=\max _{p} \frac{1}{b_{j-1}-\underline{b}}\left[(p-s)\left(b_{j-1}-b_{j}\right)+\delta_{s}\left(b_{j}-\underline{b}\right) u_{j+1}\left(s, b_{j}\right)\right]
$$

such that

$$
b_{j}-p=\delta_{b}\left(b_{j}-p_{j+1}\right) \text {. }
$$

The following lemma, which describes the solution to (DP), is due to Sobel and Takahashi (1983). The proof is by induction on $n$, and is given in the Appendix.

Lemma 2. When $s=\underline{b}$ and the buyer's valuation is uniformly distributed on $\left[\underline{b}, b_{n}\right]$, the $n$-stage bargaining game with one-sided uncertainty has a unique sequential equilibrium with the seller's expected profit $u_{j}\left(s, b_{j-1}\right)$ and price $p_{j}\left(s, b_{j-1}\right)$ with $i$ periods remaining and $j=n+1-i$ given by 


$$
\begin{aligned}
& u_{j}\left(s, b_{j-1}\right)=\frac{1}{2} c_{j} \frac{\left(b_{j-1}-s\right)^{2}}{b_{j-1}-\underline{b}} \\
& p_{j}\left(s, b_{j-1}\right)=c_{j}\left(b_{j-1}-s\right)+s
\end{aligned}
$$

where $c_{n}=\frac{1}{2}$ and for $i>1$

$$
c_{j}=\frac{\left(1-\delta_{b}+\delta_{b} c_{j+1}\right)^{2}}{2\left(1-\delta_{b}+\delta_{b} c_{j+1}\right)-\delta_{s} c_{j+1}}
$$

Moreover, the buyer's indifference valuation $b_{j}\left(s, b_{j-1}\right)$ with $i-1$ periods remaining is given by

$$
b_{j}\left(s, b_{j-1}\right)=\frac{1-\delta_{b}+\delta_{b} c_{j+1}}{\left.2\left(1-\delta_{b}+\delta_{b} c_{j+1}\right)-\delta_{s} c_{j+1}\right)}\left(b_{j-1}-s\right)+s .
$$

Equilibrium behaviour in the infinite-horizon model is derived as an immediate consequence of Lemma 2 by letting $n$ go to infinity. Actually, I need to show that the limit of the equilibrium strategies in the finite-horizon game converges to an equilibrium in the infinite-horizon game. Indeed this is the case for this game, as shown by Fudenberg and Levine (1981). Moreover, Fudenberg, Levine and Tirole (1983) show that this equilibrium is the unique equilibrium in the infinite-horizon game.

Lemma 3. When $s=\underline{b}$ and the buyer's valuation is uniformly distributed on $[\underline{b}, \bar{b}]$, then the seller's equilibrium price $p_{i}(s, \bar{b})$ in period $i$, her expected profit $u(s, \bar{b})$, and the buyer's indifference valuation $b_{i-1}$ in period $i$ are given by

$$
\begin{aligned}
p_{i} & =c(\bar{b}-s) d^{i-1}+s \\
b_{i-1} & =(\bar{b}-s) d^{i-1}+s \\
u & =\frac{1}{2} c \frac{(\bar{b}-s)^{2}}{\bar{b}-\underline{b}}
\end{aligned}
$$

where $d=c /\left(1-\delta_{b}+\delta_{b} c\right)$ and $c\left(\boldsymbol{\delta}_{s}, \boldsymbol{\delta}_{b}\right)$ is defined implicitly by

$$
c=\frac{\left(1-\delta_{b}+\delta_{b} c\right)^{2}}{2\left(1-\delta_{b}+\delta_{b} c\right)-\delta_{s} c} .
$$

The equations for $c$ and $d$ above can be solved simultaneously to yield

$$
d=\frac{1}{\delta}\left(1-\sqrt{1-\delta_{s}}\right), \quad c=\frac{d\left(1-\delta_{b}\right)}{1-\delta_{b} d} .
$$

It is easy to see that $0<c, d<1$ whenever $0<\delta_{b}, \delta s<1$.

\section{EQUILIBRIUM BEHAVIOUR WITH TWO-SIDED UNCERTAINTY}

With two-sided uncertainty, the seller must be concerned with the information her offers reveal to the buyer, and the buyer must carefully interpret offers as indications of the seller's true valuation. Here I will focus on a separating equilibrium over time in which at each stage $t$, low-valuation sellers $\left.\left(s<\hat{s}_{t}\right)\right)$ reveal completely their valuation, while high-valuation sellers pool together by offering a price so high that no buyer will accept the offer. The equilibrium is monotonic in that sellers with higher valuations offer higher prices: $p_{t}(s)$ is strictly increasing for $s \leq \hat{s}_{t}$, and constant for $s>\hat{s}_{t}$. Other equilibria are possible, such as a partition equilibrium in which $p_{t}(\cdot)$ is a step function, but such partially revealing equilibria are intractable in the infinite-horizon game. Furthermore, analysis of equilibria in the two-period model (Cramton (1983a)) suggests that the players have very little to gain by only revealing partially their information (it was found that the seller could typically 
increase her ex ante payoff by no more than one-tenth of one percent when she played the optimal partition strategy).

For those sellers that reveal completely their private information, their price schedule $p(s)$ is strictly increasing in $s$, so that the buyer is able to infer the seller's valuation by inverting $p(s)$; namely, $s=p^{-1}(p)$. Thus, the players' strategies for the remainder of the game will be as determined in the previous section where the seller's valuation is known. However, to insure incentive compatibility one must give seller $s$ the option of pretending to be some other seller $s^{\prime}$ if she so desires. Suppose at some stage of the bargaining the seller knows she is facing a buyer whose valuation is uniformly distributed on $[\underline{b}, \bar{b}]$ and she chooses to reveal (perhaps falsely) that her valuation is $s^{\prime}$. Seller $s$ will choose $s^{\prime}$ and $p=p_{0}$ so as to maximize her expected gain given that the buyer infers her valuation to be $s^{\prime}(p)$ and accepts if $b \geq \hat{b}(p)=b_{0}$ :

$$
\max _{p, s}(p-s)(\bar{b}-\hat{b})+\sum_{n=1}^{\infty} \delta_{s}^{n}\left(p_{n}-s\right)\left(b_{n-1}-b_{n}\right)
$$

subject to

1. Sequential Rationality. The seller's future offers $p_{1}, p_{2}, \ldots$ are chosen to maximize the payoff of seller $s^{\prime}$ given by the buyer's future indifference valuations $b_{1}, b_{2}, \ldots$, which are chosen so that buyer $b_{n}$ is indifferent between accepting $p_{n}$ now or waiting one period and accepting $p_{n+1}$ next period:

$$
b_{n}-p_{n}=\delta_{b}\left[b_{n}-p_{n+1}\left(s^{\prime}, b_{n}\right)\right] \quad \forall n \geq 0 .
$$

2. Incentive Compatibility. The buyer in equilibrium is not fooled:

$$
s^{\prime}(\cdot)=b^{-1}(\cdot)
$$

A few comments are in order. First, the above optimization problem applies only for the range of sellers $[\underline{s}, \hat{s}]$ that reveal completely their information (so that inversion of $p(s)$ is possible). Second, the problem as stated only allows for deviations along the equilibrium path; that is, it is initially assumed that a seller $s$ will imitate the behaviour of seller $s^{\prime}$ forever and hence never be detected as deviating from the equilibrium. Deviations off the equilibrium path are considered later in this section, when I establish conjectures that support the described equilibrium strategies. Actually, sequential rationality requires that the seller's future offers $p_{1}, p_{2}, \ldots$ be chosen to maximize the utility of seller $s$, not $s^{\prime}$. However, since the buyer believes that the seller has valuation $s^{\prime}$ and so expects to see prices that maximize the utility of seller $s^{\prime}$, if the buyer observes prices that do not maximize the utility of seller $s^{\prime}$ then his subsequent behaviour will be determined by his conjectures off the equilibrium path. I have chosen these conjectures in such a way that the seller is better off offering prices $p_{1}, p_{2}, \ldots$ that maximize the utility of seller $s^{\prime}$, rather than surprising the buyer by offering prices not along the equilibrium path. Finally, in equilibrium the buyer $b_{n}$, who is indifferent between accepting or rejecting $p_{n}$ will strictly prefer to accept $p_{n+1}$ rather than wait for $p_{n+2}$. Thus, to determine $b_{n}$ it is sufficient to equate what the buyer $b_{n}$ gets by accepting $p_{n}$ and what he gets if he waits one period and accepts $p_{n+1}$.

Two cases are possible depending on the position of the seller's valuation $s$ relative to the support $[\underline{b}, \bar{b}]$ of the buyer's valuation; however, in order to be as concise as possible, discussion will be limited to the case where $s \geq \underline{b}$. The other case is which $s<\underline{b}$ is similar except that the bargaining ends with probability one after a finite number of offers.

Suppose seller $s$ chooses to be the seller $s^{\prime}$ by offering the price $p$. Then her expected payoff is given by

$$
u_{s}\left(s^{\prime}, p\right)=\frac{1}{\bar{b}-\underline{b}}\left[(\bar{b}-\hat{b})(p-s)+\sum_{n=1}^{\infty} \delta_{s}^{n}\left(b_{n-1}-b_{n}\right)\left(p_{n}-s\right)\right]
$$

where the future prices and indifference valuations are

$$
\begin{aligned}
& p_{n}=c\left(\hat{b}-s^{\prime}\right) d^{n-1}+s^{\prime} \\
& b_{n}=\left(\hat{b}-s^{\prime}\right) d^{n}+s^{\prime}
\end{aligned}
$$

and 


$$
\hat{b}(p)=\frac{p-\delta_{b}(1-c) s^{\prime}(p)}{1-\delta_{b}+\delta_{b} c} .
$$

Thus,

$$
\begin{aligned}
b_{n-1}-b_{n} & =\left(\hat{b}-s^{\prime}\right)(1-d) d^{n-1} \\
p_{n}-s & =c\left(\hat{b}-s^{\prime}\right) d^{n-1}+s^{\prime}-s
\end{aligned}
$$

so

$$
\left(b_{n-1}-b_{n}\right)\left(p_{n}-s\right)=\left(\hat{b}-s^{\prime}\right)(1-d)\left[c\left(\hat{b}-s^{\prime}\right)\left(d^{2}\right)^{n-1}+\left(s^{\prime}-s\right) d^{n-1}\right] .
$$

Substituting into (US) and performing the summation yields

$$
u_{s}\left(s^{\prime}, p\right)=\frac{1}{\bar{b}-\underline{b}}\left[(\bar{b}-\hat{b})(p-s)(1-d)\left[c\left(\hat{b}-s^{\prime}\right) \frac{1}{1-\delta_{s} d^{2}}+\left(s^{\prime}-s\right) \frac{1}{1-\delta_{s} d}\right]\right] .
$$

It can be shown that $(1-d) /\left(1-\delta_{s} d^{2}\right)=\frac{1}{2}$ and $(1-d) /\left(1-\delta_{s} d\right)=d$, so that

$$
u_{s}\left(s^{\prime}, p\right)=\frac{1}{\bar{b}-\underline{b}}\left[(\bar{b}-\hat{b})(p-s)+\frac{1}{2} \delta_{s} c\left(\hat{b}-s^{\prime}\right)^{2}+\delta_{s} d\left(\hat{b}-s^{\prime}\right)\left(s^{\prime}-s\right)\right]
$$

Taking the derivative of $u_{s}\left(s^{\prime}, p\right)$ with respect to $\mathrm{p}$ yields the first-order condition

$$
\bar{b}-\hat{b}-\hat{b}_{p}(p-s)+\delta_{s} c\left(\hat{b}-s^{\prime}\right)\left(\hat{b}_{p}-s_{p}^{\prime}\right)+\delta_{s} d\left[\left(\hat{b}_{p}-s_{p}^{\prime}\right)\left(s^{\prime}-s\right)+s_{p}^{\prime}\left(\hat{b}-s^{\prime}\right)\right]=0
$$

where $\hat{b}_{p}$ is the derivative of $\hat{b}$ with respect to $p$ and $s_{p}^{\prime}=d s^{\prime}(p) / d p$. Making the substitutions $s^{\prime}=s$ (implied by incentive compatibility), $s_{p}^{\prime}=d s / d p, \hat{b}=(p-s) / v+s$, and $\hat{b}_{p}=(1-d s / d p) / v+d s / d p$ where $v=1-\delta_{b}(1-c)$ yields the first-order differential equation

$$
(\bar{b}-s) v^{2} \frac{d p}{d s}-(p-s)\left[2 v \frac{d p}{d s}-v+v^{2}-\delta_{s}\left(c\left(\frac{d p}{d s}-1\right)+v d\right)\right]=0
$$

which in differential form becomes

$$
(\alpha p+\beta s+\gamma) d p+\sigma(p-s) d s=0
$$

where

$$
\begin{aligned}
& v=1-\delta_{b}(1-c) \\
& \alpha=-2 v+\delta_{s} c \\
& \beta=v(2-v)-\delta_{s} c \\
& \gamma=\bar{b} v^{2} \\
& \sigma=v(1-v)+\delta_{s}(v d-c) .
\end{aligned}
$$

This differential equation is then solved to yield $p(s)$ given the initial condition $p_{0}=p(\underline{s})$, where $p_{0}$ is determined to maximize the payoff of seller $\underline{s}$ (the incentive constraint is not binding for the lowest-valuation seller). The offer function $p(s)$ implied by the differential equation is such that each seller $s$ prefers offering $p(s)$ than pretending to be any seller $s^{\prime} \neq s$ by offering $p\left(s^{\prime}\right)$. It should be noted that, due to the incentive constraint, the offer $p(s)$ is significantly higher than the offer that the seller $s$ would make had her cost been known.

Given specific values of $\delta_{s}, \delta_{b},[\underline{s}, \bar{s}]$, and $[\underline{b}, \bar{b}]$, it is possible to compute an equilibrium by the following iterative procedure. First, compute the coefficients found in Section 4, which determine the offers and indifference valuations that occur after the seller's valuation has been revealed. For the lowest-valuation seller (seller $\underline{s}$ ), determine the price she should offer and her optimal maximum number of periods of bargaining. This is easily done, since the incentive compatibility constraint is nonbinding for seller $\underline{s}$. Gradually increase $s$ from $\underline{s}$ by some small incremental step $\Delta s>0$, computing the offer function $p(s)$ so that the seller $s$ is indifferent between offering $p(s)$ and $p(s+\Delta s)$. As $s$ increases, there will eventually become a point $\hat{s}_{1}$, at which no buyer will accept 
the price $p\left(\hat{s}_{1}\right)$. All sellers with valuations $s>\hat{s}_{1}$ will offer an unacceptable price to signal that their valuations are high. In the second round, prices for sellers $\underline{s}$ to $\hat{s}_{1}$ are easily determined, since these sellers have already revealed their private information. For sellers $s>\hat{s}_{1}$, prices are determined as in the first period: the initial condition $p\left(\hat{s}_{1}\right)$ is easily determined, since the incentive compatibility constraint is nonbinding at this point; $p(s)$ then increases so that seller $s$ is indifferent between offering $p(s)$ and $p(s+\Delta s)$, up until the point where no buyer accepts the second round offer $p\left(\hat{s}_{2}\right)$. This process is repeated until the equilibrium offers of all sellers $s \in[\underline{s}, \bar{s}]$ are determined.

\section{Conjectures off the equilibrium path}

The analysis thus far has established the best-response strategies of the buyer and the seller when faced with the hypothesized equilibrium strategies. To assure that these best-response strategies do indeed form an equilibrium, one must verify that no player is better off deviating from these equilibrium strategies. How well a player can do by deviating will depend on the beliefs an opponent forms when faced with non-equilibrium behaviour. Thus to determine that the seller is better off playing the equilibrium than deviating, I must posit the conjectures a buyer makes when faced with an offer off the equilibrium path.

One has a great deal of freedom in choosing conjectures that support an equilibrium. Since every seller wishes to be thought to have high valuations, the conjecture most apt to support an equilibrium is "if an offer $p$ is not an equilibrium offer, then $s=\underline{s}$ with probability one". However, such an extreme conjecture hardly seems plausible. The conjecture should be based on reasonable inferences a buyer might make when faced with an initial offer off the equilibrium path. To determine what constitutes "reasonable inferences" in particular applications, it is helpful to look at the equilibrium strategies and have the non-equilibrium beliefs be in line with the equilibrium beliefs. In the hypothesized equilibrium discussed here, higher prices signal higher valuations. Thus, it is reasonable for the non-equilibrium conjectures to satisfy this monotonicity as well.

Describing conjectures that support an equilibrium is a complicated task in an infinite-horizon model, due to the many possibilities for deviant behaviour the multiple periods afford. A seller could pretend to be someone else for a few periods and then start acting like himself or even a third type of seller; the possibilities for nonequilibrium behaviour are practically limitless. However, one can describe a reasonably simple and intuitive set of conjectures that supports the equilibrium described here.

In the posited conjectures, the buyer's beliefs will be of the same form whether he has observed behaviour on or off the equilibrium path. Namely, at each stage of the game, the buyer either believes with probability one that the seller has valuation $s$ or he believes that the seller's valuation is uniformly distributed on the interval $[\hat{s}, \bar{s}]$.

The buyer's conjectures are defined inductively as follows. Just before the $t$-th period, the buyer believes that either $s=s_{t}<\hat{s}_{t}$ with probability one or that $s$ is uniformly distributed on $\left[\hat{s}_{t}, \bar{s}\right]$. After the $t$-th period offer $p$, the buyer revises his probabilities as follows:

(1) If the buyer believes $s \sim U\left[\hat{s}_{t}, \bar{s}\right]$ and $p \geq p_{t}\left(\hat{s}_{t+1}\right)$, then $s \sim U\left[\hat{s}_{t+1}, \bar{s}\right]$.

(2) If the buyer believes $s \sim U\left[\hat{s}_{t}, \bar{s}\right]$ and $p<p_{t}\left(\hat{s}_{t+1}\right)$, then $s=p_{r}^{-1}(p)$ where $r=\max \left\{t \mid p \in p_{t}\left(\left[\hat{s}_{t+1}, \hat{s}_{t}\right]\right)\right\}$.

(3) If the buyer believes $s=s_{t}$ and $p>p_{t}\left(s_{t}\right)$, then $s=s_{t}$.

(4) If the buyer believes $s=s_{t}$ and $p>p_{t}\left(s_{t}\right)$, then $s=p_{t}^{-1}(p)$.

This set of conjectures has two features that make it especially desirable. First, it agrees with the notion that higher offers signal higher valuations (it can be shown that this implies that the equilibrium offer functions must be monotonic). Second, it yields beliefs off the equilibrium path that are similar to the equilibrium beliefs. Thus, a buyer's behaviour changes continuously with changes in the price offered, whether or not the infinitesimal changes in price result in behaviour off the equilibrium path.

The basic idea behind these conjectures is that a high-valuation seller must be encouraged not to offer low prices initially, which are accepted by some high-valuation buyers, and then revert to higher offers in later periods. Certainly if the buyer was naive, a high-valuation seller would have an incentive to adopt such a strategy. The buyer's conjectures, however, make such an option unattractive, since the buyer when faced with nonequilibrium behaviour always tends towards optimism: when the buyer is confused by non-equilibrium behaviour, he assumes that the most optimistic information (that the seller has a low valuation) is valid. Showing that the posited conjectures support the equilibrium is a tedious task and is omitted. 
Other out-of-equilibrium beliefs will sustain this equilibrium. However, any such beliefs must be sufficiently optimistic, so as to prevent a low-valuation seller from pretending to have a higher valuation and then reverting to a strategy with lower offers.

An example

As an example, consider the case when the seller's cost is uniformly distributed on $[0,1]$ and the buyer's valuation is uniformly distributed on $\left[\frac{1}{2}, \frac{3}{2}\right]$ with $\delta_{s}=\delta_{b}=0.75$, as shown in Figure 1. (Understanding this complicated figure is helpful to understanding the form of the equilibrium.) For $s<0.14$, the bargaining ends after two periods and the incentive compatibility constraint is nonbinding. For $s>0.14$, the incentive compatibility constraint is binding, which implies that the seller offers higher prices than she would had her costs been known to the buyer. This is as one would expect: the seller has an incentive to offer an inflated price to fool the buyer into believing her cost is greater than it actually is. The buyer, however, recognizes the seller's incentive to overstate her true cost, and so appropriately discounts the inflated offer. At $s=0.52$ the seller offers a price so high that no buyer accepts. All sellers with higher costs wait until subsequent periods to reveal their private information. Thus, sellers $s \in[0,0.52]$ reveal completely their information in the initial round of negotiations; sellers $s \in[0.52,0.67]$ reveal their information in the second period; sellers $s \in[0.67,0.80]$ reveal their information in the third period, and so on. Every seller reveals her information by the end of the fifth period.

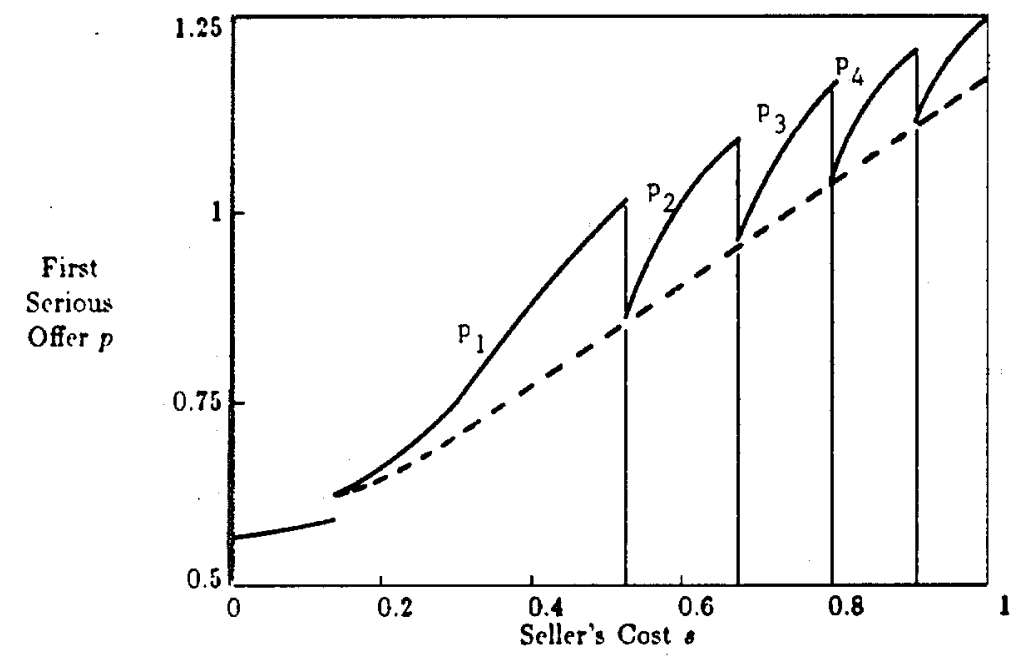

FIGURE 1

A separating equilibrium over time.

Two sided uncertainty, ...... one sided uncertainty.

It is interesting to compare the seller's equilibrium behaviour in the infinite-horizon model with her behaviour in the two-period model (Cramton (1983a)). In the two-period model, the seller is able to reveal completely her information in the first round regardless of her valuation; whereas, in the infinite-horizon model some sellers take up to five rounds to reveal their information. This is because when the seller only makes two offers, the seller's incentive to deceive in the initial period is reduced. Second, the seller offers higher prices in the two-period game than in the infinite-horizon game, since she is able to commit to ending the bargaining with a "take it or leave it" offer in the second period. In the infinite-horizon model, no such commitment is possible, so the seller is forced to offer lower prices.

\section{CONCLUSION}

In any realistic bargaining setting the issue of information, timing, and commitment are of crucial importance. Informational differences among agents often lead to inefficient bargaining outcomes and deadlocked negotiations. Time pressures tend to force an early resolution of the bargaining conflict. And the ability of agents to commit to particular strategies often determines how the gains from trade are divided among the agents. In this paper, I have presented an infinite-horizon bargaining model that explicitly considers information and timing in 
bargaining settings in which the players are unable to make binding commitments. Rational behaviour on the part of the agents has been characterized for the class of uniform distributions under various information structures.

The results of the example are intuitively appealing. When the agents have complete information an efficient agreement is immediately reached. When only the buyer has complete information, trade frequently occurs only after costly delay. Moreover, the buyer benefits from his superior information. When both the buyer and the seller are unsure of the other's preferences, the outcome is even less efficient, due to the seller's incentive to deceive the buyer. How much information the seller reveals in each round of negotiations depends on the players' costs of delay: when delay costs are high, much information is revealed each period; whereas, when the costs of delay are small, less information is revealed. Due to the seller's incentive to lie about her costs, the seller must offer higher prices than she would had the buyer known her valuation. These higher prices lead to significant inefficiencies: roughly $25 \%$ of the potential gains from trade are lost in a typical example.

Both the degree of uncertainty and impatience affect the bargaining outcome. (In this example, I am measuring the degree of uncertainty by the amount of overlap of the supports of two uniform distributions of equal length. Thus, uncertainty is greatest when the supports are identical, and uncertainty declines as the buyer's support moves to the right. This definition of uncertainty is not meant to be general, but is serves well in this example.) Uncertainty has a detrimental effect on bargaining efficiency-the more uncertainty present, the less efficient the bargaining outcome. Moreover, the percentage of the gains from trade going to the offeror decreases as uncertainty increases. Thus, when the gains from trade are highly uncertain it is best to let one's opponent make the offers (and reveal valuable information about his reservation price), but when the gains from trade are known it is best to make the offers. In contrast, the players' discount factors have an ambiguous and often subtle effect on the bargaining outcome: higher costs of delay will increase the probability of an early agreement, but reduce the benefit of a delayed agreement. Regardless of the degree of uncertainty, increasing delay costs benefits the seller and hurts the buyer, because with higher delay costs the seller can force the buyer to accept higher prices. Thus, one would expect the seller to choose to lengthen the time between offers; whereas, the buyer would prefer offers to be made in rapid succession.

Although the equilibrium derived here is not unique, it is a unique sequential equilibrium within the class of separating-over-time strategies in which lower valuation sellers make attractive offers (strictly increasing in $s$ ), while higher valuation sellers simply delay negotiations. A good candidate for an alternative equilibrium is as follows. At time zero, the seller makes an offer that partitions the potential sellers into a finite set of subintervals. For example, the seller by making the offer $p_{i}$ reveals that her valuation is in $\left[s_{i-1}, s_{i}\right]$. After this initial revelation, they continue to bargain by following the "separating-over-time equilibrium" derived in this paper. It remains to verify whether or not such a "partition equilibrium" exists.

An important feature of the bargaining game presented here, is that it makes no assumptions about the bargainers' ability to commit to future strategies: the players continue to negotiate so long as they expect positive gains from continuing. Implicit in some bargaining mechanisms is the assumption that the bargainers are able to commit to walking away from the negotiating table, even when it is common knowledge that the gains from trade are positive. The simultaneous-offer game (Chatterjee and Samuelson (1983)) is an example of such a mechanism. Although this game is more efficient ex ante, it ends with positive probability in a state in which both bargainers know that gains from trade exist (since their respective reservation prices have been revealed), and yet they are forced to walk away from the bargaining table. The infinite-horizon game has the desirable property that trade occurs if and only if gains from trade exist; hence, all potential gains are realized, but often only after costly delay.

It is somewhat disappointing that the dynamic bargaining game is not more efficient ex ante. When the players' reservation prices are uniformly distributed on $[0,1]$ and their discount factors are equal, this game results in at least $32 \%$ of the gains from trade being lost, as opposed to a $16 \%$ loss if the ex ante efficient bargaining mechanism is adopted. Thus, requiring sequential rationality has both benefits and costs. The benefit is an absence of ex post regret (all potential gains are realized), and the cost is reduced ex ante efficiency.

One limitation of this analysis is the assumption that only one of the bargainers can make offers. In most practical situations, both traders will be able to make offers. The game with alternating offers has been analysed by Rubinstein (1982) in a setting of complete information, and by Rubinstein (1983) when one of the bargainers has either a low or high discount factor. Cramton (1984) looks at a continuous-time version of the alternatingoffer game with two-sided incomplete information. The continuous-time game permits a general bargaining rule: at every instant, a bargainer can make a new offer or accept the most recent offer of his opponent. The equilibrium constructed in the continuous-time game follows intuitively from the discrete-time analysis presented here. Moreover, the results in the alternating-offer game support the basic results found in this paper. 


\section{APPENDIX}

Proof of Lemma 2. The proof is by induction on $n$. With one period remaining, the seller wishes to choose $p$ according to the programme

$$
u_{n}\left(s, b_{n-1}\right)=\max _{p}(p-s) \frac{b_{n-1}-p}{b_{n-1}-\underline{b}}
$$

so $p_{n}\left(s, b_{n-1}\right)=\frac{1}{2}\left(b_{n-1}+s\right)=\frac{1}{2}\left(b_{n-1}-s\right)+s$ and $u_{n}\left(s, b_{n-1}\right)=\frac{1}{4}\left(b_{n-1}-s\right)^{2} /\left(b_{n-1}-\underline{b}\right)$.

With $i$ periods remaining, the seller's expected profit is given by

$$
u_{j}\left(s, b_{j-1}\right)=\max _{p} \frac{1}{b_{j-1}-\underline{b}}\left[(p-s)\left(b_{j-1}-b_{j}\right)+\delta_{s}\left(b_{j}-\underline{b}\right) u_{j+1}\left(s, b_{j}\right)\right]
$$

such that

$$
b_{i}-p=\delta_{b}\left(b_{j}-p_{j+1}\right)
$$

Assume by the induction hypothesis that

$$
u_{j+1}\left(s, b_{j}\right)=\frac{1}{2} c_{j+1} \frac{\left(b_{j}-s\right)^{2}}{b_{j}-\underline{b}} .
$$

Then $p=\left(1-\delta_{b}\right) b_{j}+\delta_{b}\left[c_{j+1}\left(b_{j}-s\right)+s\right]$, or

$$
p=\left(1-\delta_{b}+\delta_{b} c_{j+1}\right)\left(b_{j}-s\right)+s .
$$

Substituting into (1) yields

$$
u_{j}\left(s, b_{j-1}\right)=\max _{b_{j}} \frac{1}{b_{j-1}-\underline{b}}\left[\left(1-\delta_{b}+\delta_{b} c_{j+1}\right)\left(b_{j}-s\right)\left(b_{j-1}-b_{j}\right)+\frac{1}{2} \delta_{s} c_{j+1}\left(b_{j}-s\right)^{2}\right]
$$

which has a unique maximum when

$$
\left[2\left(1-\delta_{b}+\delta_{b} c_{j+1}\right)-\delta_{s} c_{j+1}\right] b_{j}=\left(1-\delta_{b}+\delta_{b} c_{j+1}\right)\left(b_{j-1}+s\right)-\delta_{s} c_{j+1} s .
$$

(A necessary and sufficient condition for strict concavity of $u_{j}$ is $\delta_{b}\left(1-c_{j+1}\right)+\frac{1}{2} \delta_{s} c_{j+1} \leq 1$. This is clearly satisfied, since $\delta_{s}, \delta_{b}$, and $c_{j+1}$ are between 0 and 1.) So,

$$
b_{j}=\frac{1-\delta_{b}+\delta_{b} c_{j+1}}{2\left(1-\delta_{b}+\delta_{b} c_{j+1}\right)-\delta_{s} c_{j+1}}\left(b_{j-1}-s\right)+s
$$

Thus by substituting (4) into (2) and (3) we get

$$
p_{j}\left(s, b_{j-1}\right)=\frac{\left(1-\delta_{b}+\delta_{b} c_{j+1}\right)^{2}}{2\left(1-\delta_{b}+\delta_{b} c_{j+1}\right)-\delta_{s} c_{j+1}}\left(b_{j-1}-s\right)+s,
$$

and

$$
u_{j}\left(s, b_{j-1}\right)=\frac{1}{2} \frac{\left(1-\delta_{b}+\delta_{b} c_{j+1}\right)^{2}}{2\left(1-\delta_{b}+\delta_{b} c_{j+1}\right)-\delta_{s} c_{j+1}} \frac{\left(b_{j-1}-s\right)^{2}}{b_{j-1}-\underline{b}}
$$

as required. $\quad \|$ 
First version received August 1983, final version accepted March 1984 (Eds.).

I am indebted to Robert Wilson for his encouragement and advice. My thanks to Robert Gibbons, Jean Tirole, and two anonymous referees for their helpful comments.

REFERENCES

CHATTERJEE, K. and SAMUELSON, W. (1983), "Bargaining under incomplete information", Operations Research, 31, 835-851.

CRAMTON, P. C. (1983), "Bargaining with incomplete information: a two-period model with continuous uncertainty" (Research Paper No. 652, Stanford Graduate School of Business).

CRAMTON, P. C. (1983), "Sequential bargaining mechanisms", forthcoming in Game Theoretic Models of Bargaining (Cambridge University Press).

CRAMTON, P. C. (1984), "The role of time and information in bargaining" (Research Paper No.721, Stanford Graduate School of Business).

FUDENBERG, D. and LEVINE, D. (1981), "Sequential equilibria of finite and infinite horizon games", Journal of Economic Theory (forthcoming).

FUDENBERG, D., LEVINE, D. and TIROLE, I. (1983), "Infinite-horizon models of bargaining with onesided incomplete information", forthcoming in Alvin Roth, (ed.) Game Theoretic Models of Bargaining (Cambridge University Press).

FUDENBERG, D. and TIROLE, I. (1983), "Sequential bargaining with incomplete information", Review of Economic Studies, 50, 221-247.

HARSANYI, J. C. (1967), "Games with incomplete information prayed by Bayesian players, I-III", Management Science, 14, 159-183, 320-334, 486-502.

HOLMSTROM, B. and MYERSON, B. (1983), "Efficient and durable decision rules with incomplete information “, Econometrica, 51, 1799-1820.

KREPS, D. M. and WILSON, R. (1982), "Sequential equilibria”, Econometrica, 50, 863-894.

MYERSON, R. B. and SATTERTHWAITE, M. A. (1983), "Efficient mechanisms for bilateral trading", Journal of Economic Theory, 28, 265-281.

RUBINSTEIN A. (1982), "Perfect equilibrium in a bargaining model”, Econometrica, 50, 97-109.

RUBINSTEIN A. (1983), “A bargaining model with incomplete information”, Econometrica (forthcoming).

SOBEL, I. and TAKAHASHI, 1. (1983), "A multi-stage model of bargaining”, Review of Economic Studies, 50, 411-426.

SPENCE, A. M. (1974), Market Signalling: Informational Transfer in Hiring and Related Screening Processes (Harvard University Press). 